\title{
Study of haematological parameters in malaria: a prospective study
}

\author{
Babariya MJ. ${ }^{1}$, Parmar JS. ${ }^{2 *}$ \\ DOI: https://doi.org/10.17511/jopm.2020.i01.04 \\ 1 Manjula J Babariya, Assistant Professor, Department of Microbiology, Banas Medical College and Research Institute, Palanpur, Gujarat, \\ India. \\ 2* Jitendrakumar S. Parmar, Assistant Professor, Department of Pathology, Banas medical College and Research Institute, Palanpur, Gujarat, \\ India.
}

Background: A blood parasites plasmodia is responsible for malaria hence there are haematological alterations in malaria. The haematological changes that have been reported to accompany malaria include anaemia, thrombocytopenia, leucocytosis and leucopenia. Methods: Total 585 smear positive malaria cases were taken and various haematological parameters were studied. Results: Out of 585 smear positive cases, $P$. vivax was positive in 422 (72\%) cases, while $P$. falciparum was positive in $160(27 \%)$ cases and mixed infection was found in $3(1 \%)$ cases. Anaemia was seen in $420(71.79 \%)$ cases. Normocytic normochromic blood picture was the most common type in anaemic patients 223 (38.11\%). Next common finding was Normocytic hypochromic RBCs 185 (31.62\%). Microcytic hypochromic RBCs found in 152 (25.98\%) cases. Thrombocytopenia was seen in total $490(83.76 \%)$ of the patients. Moderate thrombocytopenia was more common and present in 409 (70\%) of patients while Severe thrombocytopenia was seen in $81(13.84 \%)$ of cases. Conclusions: Various haematological findings can help in early diagnosis of malaria which is essential for timely and appropriate treatment which can limit the morbidity and prevent further complications.

Keywords: CBC, Haematological-parameters, Malaria, Thrombocytopenia

\section{Corresponding Author}

Jitendrakumar S. Parmar, Assistant Professor, Department of Pathology, Banas medical College and Research Institute, Palanpur, Gujarat, India.

Email: jitspath@gmail.com

\section{How to Cite this Article}

Manjula J Babariya, Jitendrakumar S. Parmar, Study of haematological parameters in malaria: a prospective study. Trop J Pathol Microbiol. 2020;6(1):23-29.

Available From

https://pathology.medresearch.in/index.php/jopm/ar ticle/view/384
To Browse

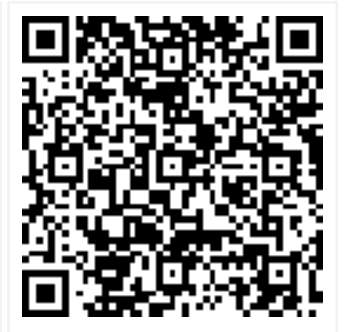

\section{Introduction}

Malaria is a protozoal disease caused by infection with parasites of genus plasmodium. These protozoa comprise 5 species $P$. falciparum, $P$. vivax, $P$. malariae, $P$. ovale and $P$. knowlesi (a parasite of long tailed Macaque monkeys may also affect man). Malaria is

Manuscript Received 10-12-2019

Conflict of Interest No

Review Round 1
20-12-2019
Funding
Nil

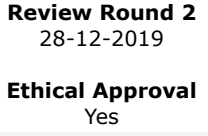

Ethical Approval Yes

Most important disease in human in terms of geographical distribution, morbidity and mortality. More than 100 countries in world are considered malarious, and more than 2.4 billion of world's population are at risk. The world annual incidence of malaria is about 300-500 million cases. Malaria kills 1.1 to 2.7 million people annually [1]. (c) 2020 by Manjula J Babariya, Jitendra kumar S. Parmar and Published by Siddharth Health Research and Social Welfare
Society. This is an Open Áccess article licensed under a Creative Commons Attribution 4.0 International License https://creativecommons.org/licenses/by/4.0/ unported [CC BY 4.0].

\author{
Review Round 3 \\ Placher \\ $18 \%$
}

Accepted 02-01-2020

Note 
In India malaria continue to pose a major public health threat particularly due to Plasmodium falciparum which is prone to complication. In India about $27 \%$ population lives in malaria high transmission areas (>1cases/1000 population) and about $58 \%$ in low transmission areas. (0-1 case / 1000 population). Malaria surveillance for the period from 1995 to 2011 is shown that API (Annual parasite rate) has been steadily declining in India from 3.29 in 1995 to 1.10 in 2011 [2]. Malaria causing plasmodium are parasites of blood and hence induce haematological alterations [3]. The anaemia is caused by excess removal of nonparasitized erythrocytes in addition to immune destruction of parasitized red cells, and impaired compensation for this loss by bone marrow dysfunction $[4,5]$. Thrombocytopenia is a common finding in falciparum and vivax malaria. Enhanced splenic uptake or sequestration may contribute to thrombocytopenia. In immune mediated thrombocytopenia, IgG forms a complex with the malarial antigen, the complex binds to and damages circulating platelets which are then removed from the circulation $[6,7,8]$. Mild leucopenia has been described in uncomplicated malarias, but a neutrophilic leucocytosis is an important abnormality in patients with severe falciparum malaria and is associated with a bad prognosis. TNF-a may be responsible for this leucocytosis, which may be associated with a complicating bacteraemia. The other common changes seen are monocytosis found in population living in endemic areas $[4,9,10,11]$.

The aim is to study the changes in haematological parameters in smear positive malaria cases.

\section{Methods}

Study type: Prospective study

Study duration: 1st June 2013 to 31 st May 2014

Location: Tertiary Care Hospital at Ahmedabad

Total 585 patients showing smear positivity for one or more species of malaria parasite were included. The blood samples of these patients were subjected for following laboratory investigations.

CBC was carried out in RUBY Five-part Differential Automated Haematology Analyser and following readings were noted.

Haemoglobin (HB\%), HCT (haematocrit), Total leucocyte count (TLC), Differential leucocyte and
Platelet count.

01. Rapid Test (Malarial Ag detection) 2. Thin and Thick peripheral smear

Rapid Test Kit for Malaria Ag Pf /Pan (HRP-2/p LDH) (Paracheck, Alere Trueline TM)

All samples were first tested by Rapid Test Kit for Malaria Ag Pf/Pan (HRP-2/p-LDH). The Alere Trueline TM Rapid Test Kit for Malaria Ag Pf/Pan (HRP-2/p-LDH) is one step rapid qualitative and differential test for test detection of HRP-2. (Histidine Rich Protein-2) specific to Plasmodium falciparum and $\mathrm{p}$-LDH (Plasmodium lactate dehydrogenase) pan specific to Plasmodium species in human blood specimen.

This kit is intended for the detection of Malarial infection in human blood sample, indicating differential diagnosis between Pf.

HRP-2 (Histidine Rich Protein-2) and other Plasmodium species (Pan, $\mathrm{p}$-LDH) ( $P$. vivax, $P$. malaria, $P$. ovale) This kit was use as a screening test and all reactive sample were confirmed by microscopic examination of thin blood smear .

\section{Test procedure}

01. Bring all kit components and specimens to room temperature prior to testing.

02. Remove the test device from foil pouch, place it on the dry and flat surface.

03. Take EDTA blood sample of patient or clean the fingertip and prick the finger with the lancet.

04. With $5 \mu$ lisposable loop is provided, dip the circular end of loop into the blood specimen and carefully place the circular end into the round end sample well.

05. Add 4 drops of assay diluent into square assay diluent well.

06. Interpret test result within 20-30 minutes.

Caution: Don't read the test result after 30 minutes.

\section{Interpretation of Result}

Negative: Presence of only one colour band (" $\mathrm{C}$ " Control band) within the result window.

\section{Positive:}

01. $P$. falciparum positive: Presence of two-colour band ("C" Control line \& "P.f."" test line) or three colour band ("C" Control line,"P.f."" and "Pan" test line) within the result window. 


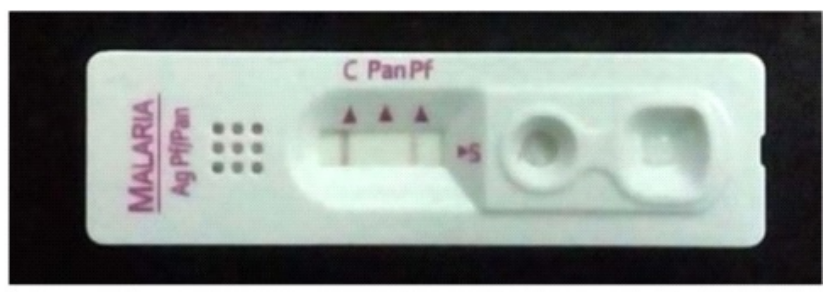

02. Other plasmodium species (P.v, P.m, P.o) positive: Presence of two-colour band ("C" Control line \& "Pan" test line) within the result window.

03. Mixed infection: Presence of three colour band ("C" Control line "P.f."" \& "Pan" test line) within the result window may indicate mixed infection.

Invalid result: If control band ("C" Control line) fails to appear within the result window the result is considered invalid.

Method of preparing Thick and thin smear:

The thin film: Take a single small drop of blood from EDTA sample on the middle of clean glass slide, blood was spread using a spreader slide at angle of 450 over the length.

The thick film: Place two or three larger drops of blood from EDTA sample on the slide, about $1 \mathrm{~cm}$ away from the drop intended for the thin film. Handling the slide by the edges or a corner, make the blood film by using the corner of the spreader to join the drops of blood, and spread them to make an even, thick film. Do not stir the blood. A circular or rectangular film can be made by three to six quick strokes with the corner of the spreader. The circular thick film should be about $1 \mathrm{~cm}$ in diameter.

The thick film should be dried and be protected from dust, flies, sunlight and extreme heat. Thick smear can be prepared on separate slide [12]. Slides were fixed and stained with Field's Stain. Peripheral blood smear examination was done systematically under low, high and oil immersion of microscope for

- RBC morphology

- Total leucocyte count

- Platelet adequacy

- Type of malarial parasite

- Grading of malaria

\section{Results}

Total 585 smear positive malaria cases were taken and various haematological parameters were noted. Out of 585 smear positive cases, $P$. vivax was
Positive in $422(72 \%)$ cases while $P$. falciparum was positive in $160(27 \%)$ cases and mixed infection was found in $3(1 \%)$ cases. Out of 585 cases, $P$. vivax was the most common observed species. Next common was $P$. falciparum (Figure 1 ).

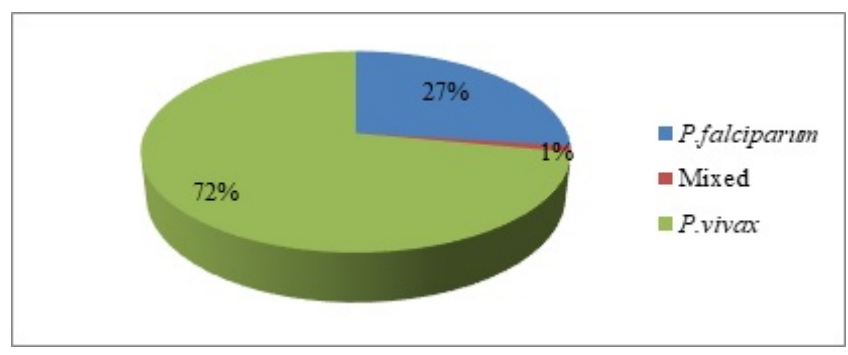

Fig-1: Distribution of plasmodium species in population.

Age distribution: As shown in the Table 1, most of the cases $(52.75 \%)$ were in the young adults between 21-40 years age group. People of all age groups were seen, youngest one was 3-month-old male child with $P$. vivax infection along with dengue and oldest was 92 years old male with $P$. falciparum infection.

Table-1: Age distribution of malarial patient.

\begin{tabular}{|l|l|l|}
\hline \multicolumn{1}{|c|}{$\begin{array}{c}\text { Age Group } \\
\text { (Years) }\end{array}$} & \multicolumn{1}{|c|}{$\begin{array}{c}\text { No of patients }(\mathrm{n=584}) \mathbf{1} \text { is below } \mathbf{1} \\
\text { year }\end{array}$} & $\begin{array}{l}\text { Percentag } \\
\text { e }\end{array}$ \\
\hline 1 to 10 & 49 & 8.50 \\
\hline 11 to 20 & 57 & 9.70 \\
\hline 21 to 30 & 156 & 26.60 \\
\hline 31 to 40 & 153 & 26.15 \\
\hline 41 to 50 & 76 & 13 \\
\hline$>50$ & 93 & 15.89 \\
\hline
\end{tabular}

Table-2: Sex distribution of malaria parasites.

\begin{tabular}{|l|l|l|}
\hline \multicolumn{1}{|c|}{ Malarial species } & \multicolumn{1}{c|}{ Male $(\mathrm{n}=\mathbf{3 7 7})$} & \multicolumn{1}{c|}{ Female $(\mathrm{n}=\mathbf{2 0 8})$} \\
\hline P. falciparum & 111 & 49 \\
\hline P. vivax & 265 & 157 \\
\hline Mixed & 1 & 2 \\
\hline
\end{tabular}

As shown in Table 2, both types of Malaria cases were more common in male.

\section{Hematological parameters}

Haemoglobin concentration (Hb\%): Majority, $71.79 \%$ (420) cases of the patients had $\mathrm{Hb}$ level $<11 \mathrm{gm} / \mathrm{dl}$, out of which $49.40 \%$ (289) belong to $P$. vivax and $21.88 \%$ (128) to $P$. falciparum.

Platelet count: Decreased platelet counts was a constant feature of both types of malaria with $69.91 \%$ (409) of cases showing platelets from 50,000 to 1.5 lacs. Severe platelet reduction $(<50000)$ was seen in $13.84 \%$ (81) cases (Table 3 ). 
Table-3: Platelet count.

\begin{tabular}{|l|l|l|l|l|l|}
\hline \multicolumn{1}{|c|}{$\begin{array}{c}\text { Platelet Count } \\
(\mathbf{n = 5 8 5})\end{array}$} & $\begin{array}{c}\text { P. } \\
\text { vivax }\end{array}$ & \multicolumn{1}{|c|}{$\begin{array}{c}\text { P. } \\
\text { falciparum }\end{array}$} & $\begin{array}{c}\text { Mixed } \\
\text { infection }\end{array}$ & Total & $\mathbf{( \% )}$ \\
\hline 50,000 & 42 & 37 & 2 & 81 & 13.84 \\
\hline $50,000-1.5$ lacs & 301 & 107 & 1 & 409 & 69.91 \\
\hline $1.5-4.5$ lacs & 79 & 16 & 0 & 95 & 16.23 \\
\hline
\end{tabular}

WBC Count - (normal value: 4,000 to 11,000 per $\mathbf{c m m}$ ): $22.05 \%$ (129) cases showed WBC Count $<4000$ of which $13.84 \%$ (81) belong to $P$. vivax $7.69 \%$ (45) to $P$. falciparum, and $3(1 \%)$ were belong to mixed infection

RBC Count - in male (normal value: $\mathbf{4 . 5}$ to $\mathbf{5 . 9}$ million/per cmm): $56.23 \%$ (212) cases showed RBC count $<4.5$ million/per $\mathrm{cmm}$ of which $35.80 \%$ (135) belong to $P$. vivax and $20.15 \%$ (76) to $P$. falciparum.

RBC Count -in female (normal value: $\mathbf{4 . 5}$ to $\mathbf{5 . 1}$ million/per $\mathbf{c m m}$ ): $72.11 \%$ (150) cases showed RBC count $<4.5$ million/per $\mathrm{cmm}$ of which $53.36 \%$ (111) belong to $P$. vivax and $17.78 \%$ (37) to $P$. falciparum.

HCT (Haematocrit)\% -In male patients (Normal value: $\mathbf{4 1 . 5}$ to $\mathbf{5 0 . 4 \%}$ ):59.68\% (225) cases showed haematocrit value $<41.5 \%$ of which $38.99 \%$ (147) belong to P. vivax and $20.42 \%$ (77) to $P$. falciparum.

HCT (Haematocrit)\% - In female patients (Normal value 35.9 to $44.6 \%$ ):

$40.38 \%$ (84) cases showed Haematocrit value $<35.9 \%$ of which $27.88 \%$ (58) belong to $P$. vivax and $12.02 \%$ (25) to $P$. falciparum.

Finding of thick smear- $39.69 \%$ patients had Grade II infection which forms the majority of the cases. Most common finding was normocytic normochromic RBCs found in $38.11 \%$.

Malaria dengue coinfection: Total 24 patients were found with co infection of which 16 had $P$. vivax, and 7 had $P$. falciparum infection (Table 4 ).

Table-4: Malaria dengue coinfection.

\begin{tabular}{|l|l|l|l|}
\hline Malaria Dengue Coinfection & P. vivax & P. falciparum & mixed \\
\hline
\end{tabular}

\begin{tabular}{|l|l|l|l|}
\hline 24 & 16 & 7 & 1 \\
\hline
\end{tabular}

Mortality: As shown in Table 5, mortality rate was higher in $P$. falciparum infection. Out of 22 deaths, 6 were due to Multiple organ failure, 4 due to Cerebral malaria, 4 due to Renal failure, 3 due to Respiratory failure, 2 due to increased Intra cranial pressure in $P$. vivax infection, 2 due to Cardiogenic shock and 1
Due to Eisenmenger syndrome with VSD in $P$. vivax infection. One patient died due to Dengue and Malarial Coinfection.

\section{Table-5: No of death.}

\begin{tabular}{|l|l|l|}
\hline \multicolumn{1}{|c|}{ Types of parasites } & No of Death & \multicolumn{1}{c|}{ Percentage } \\
\hline P. vivax (422) & 9 & 2.13 \\
\hline P. falciparum (155) & 13 & 8.38 \\
\hline Mixed (8) & 0 & 0 \\
\hline Total (585) & 22 & 3.76 \\
\hline
\end{tabular}

\section{Discussion}

Malarial parasite enters human body through bite of anopheles mosquito. The various factors which are the determinants of rate of transmission include temperature and humidity. Optimum temperature for sporogony is $25^{\circ} \mathrm{C}$ to $30^{\circ} \mathrm{C}$ and it ceases below $16^{\circ} \mathrm{C}$. Rain is related to humidity and saturation. The deficit of both affects mosquito survival. Adult vector longevity increases with humidity over 60 $\%$.Manmade environmental changes and agricultural pattern with construction of dams, formation of reservoirs and irrigation systems increase the risk to human settlements by providing a breeding space for larvae of the vector.After entering to human malarial parasite targeting liver cells and red blood cells. It then multiplies and develops morphologically in infected cells ultimately resulting in necrosis and rupture of infected cells. Haemolysis and liver cell necrosis result in anaemia and jaundice. The pathophysiology of malaria results from

- Destruction of erythrocyte

- Liberation of parasite and

- Invasion of erythrocyte by merozoites. The binding of parasitized red blood cell (RBC) to uninfected red blood cell (Rosetting).

- Binding of parasitized red blood cells to endothelial cells in critical organ (cytoadherence)

- The induction of pro-inflammatory response cytokines most notably tumor necrosis factor (TNF-a)

- The host reaction to these events

- Sequestration of parasites in microcirculation of vital organs interfering with microcirculatory flow and host metabolism.

Malaria is the third most common of these diseases in India after diarrhoea and typhoid. 
Gujarat ranks 5th in the total number of malaria cases in the country [13]. Severe malaria is a disorder that affects several tissues and organs. Metabolic acidosis is recognized as a principal pathophysiological feature that is seen in the classical clinical syndromes of cerebral malaria and severe malarial anaemia. Individuals affected with malaria are dehydrated and relatively hypovolaemic which exacerbates microvascular obstruction by reducing perfusion pressure. The destruction of RBCs also part of malaria, and anaemia further compromises oxygen delivery. In case of $P$. falciparum other organs like brain and kidney are also affected. In Present study the incidence was $5.33 \%$ of which $72.13 \%$ were $P$. vivax and $27.35 \%$ were $P$. falciparum, which was comparable to study by Paltial Palat et al [14] done in Ahmedabad, Gujarat in year 2011-12 showing 69\% and 31\% respectively for both the species. In study conducted by Shraddha M. Kevadiya et al [15] overall slide positivity rate was $15.01 \%$, slide $P$. falciparum rate was $38.32 \%$, while $P$. vivax comprised of $69.68 \%$ cases of malaria \& mixed infection of $P$. vivax and $P$. falciparum was seen in $1 \%$ of cases. Study done by Pankti D. Panchal et al [16] shows $64 \%$ of cases are due to $P$. vivax and $35 \%$ of total cases are due to $P$. falciparum, which was also comparable to the present study. The most common age group affected in present study was 21 to 40 years $(52.75 \%)$. This was comparable to study by Sunita et al [17] (60\%). In Paltial Palat et al [14] Infection was commonest in both vivax and falciparum (63.13\%) between 16 and 40 years of age which was also comparable to the present study. Young adults were more prone to infection due to their increased mobility. $71.79 \%$ (420) patients were having low Haemoglobin below 11 $\mathrm{gm} / \mathrm{dl}$ in present study, which was comparable to Bashwasri et al [18] \& Sharma et al [5] showing $94.4 \%$ and $86.7 \%$ respectively. In study conducted by Richard MW et al [19] in London only $15 \%$ cases of malaria show anaemia which was vary less in comparison to the present study. Decreased HCT found in 59.68\% (225) in male patients \& $40.38 \%$ (84) in female patients which was less than found in Bashwari et al [18] (71.50\%). Leucopenia was found in 22.05\% (129) patient which was higher than found in Bashawri LAM et al [18] which shows leucopenia in $13.3 \%$ of the total malaria cases. Study done by Echieverri $M$ et al [20] had $29 \%$ cases of leucopenia in vivax malaria cases. Thrombocytopenia was found in $83.76 \%$ (490) patients which was comparable to Horstman et al
[6] \& which was more than found in Bashwari et al [18] with $55.6 \%$ The prevalence of thrombocytopenia was $78.4 \%$ of the cases studied by UM Jadhav et al [21] which was also comparable to the present study. In present study most common finding was Normocytic normochromic RBCS $38.11 \%$ comparable to $47.3 \%$ found in Shamim Akhtar et al [22] study. Next common finding was normocytic hypochromic RBCS $31.62 \%$ (185), which was comparable to Shamim Akhtar et al [22] study.

In the present study, Microcytic hypochromic RBCS found in $25.98 \%$ (152). Microcytic hypochromic anaemia found in Bashwari et al [18] was $17.7 \%$, which was less than that found in the present study. Incidence of anaemia and severity of anaemia were more observed in $P$. falciparum cases compared to $P$. vivax cases. In present study, it was observed that co-infection with dengue $4.10 \%$ (24 patients) of which one was youngest, one 3 months old male child showing marked thrombocytopenia. One patient died due to coinfection with dengue and malaria with multiorgan failure.

Limitation of study: The main limitation of this study is a confounding factor that may affect hematological parameters such as bacterial, virus, and helminth infections, micronutrient deficiencies, and genetic backgrounds of patients.

\section{Conclusion}

Malaria is one of the most common infections in Indian Subcontinent. In the present study incidence of malaria is $5.33 \%$. Malaria affects mostly adults with male predominance in the present study. Most common finding of peripheral smear in the present study was normocytic normochromic RBCs found in $38.11 \%$. In the present study, though a greater number of cases are due to $P$. vivax but more death occurred due to $P$. falciparum. In a patient with febrile illness, observation of thrombocytopenia warrants careful search for malaria parasite. Coinfection with dengue can increase the morbidity and mortality so prompt treatment should be given.

\section{What the study adds to the existing knowledge?}

Though the present study is not adding novel information to the existing literature, yet it confirms to the existing information about correlation of various haematological finding with peripheral 
Smear for early diagnosis of malaria which is essential for timely and appropriate treatment which can limit the morbidity and prevent further complications.

\section{Author's contribution}

Dr. Manjula J. Babariya and Dr. Jitendrakumar S. Parmar prepared discussion and arranged references in order and also prepared manuscript.

\section{Reference}

01. Taylor TE, Strickland GT. Malaria In- Strickland's infectious Disease. 4th ed, London- Wiley. 2006;614-642.

[Crossref]

02. Park K. Malaria In Preventive and Social Medicine. 17th ed, Jabalpur Publishers Banarsidas Bhanot Publishers. 2002;192-201. [Crossref]

03. Surve KM, Kulkarni AS, Rathod SG, Bindu RS. Study of haematological parameters in malaria. Int J Res Med Sci. 2017;5(6)2552-2557.

doi: [Article:http://dx.doi.org/10.18203/23206012.ijrms20172446][Crossref]

04. Rojanasthein S, Surakomolleart V, Boonpucknavig S, Isarangkura P. Hematological and coagulation studies in malaria. J Med Assoc Thai. 1992;75(1)190-194.

[Crossref]

05. Sharma SK, Das RK, Das BK, Das PK. Haematological and coagulation profile in acute falciparum malaria. J Assoc physicians India. 1992;40(9)581-583.

[Crossref]

06. Horstmann Rd, Dietrich M, Bienzle U, Rasche. H malaria induced thrombocytopenia. Blut. 1981;42(3)157-164.

[Crossref]

07. Makkar Rps, Mukhopadhyay S, Monga A, Gupta A. Plasmodium vivax malaria presenting with severe thrombocytopenia. Braz J Infect Dis. 2002;6(5)263-265.

[Crossref]

08. Kakar A, Bhoi S, Prakash V, Kakar S. Profound thrombocytopenia in plasmodium vivax malaria. Diagn Microbiol Infect Dis. 1999;35(3)243-244. doi:[Article:https://doi.org/10.1016/s0732-8893(99) 00069-3][Crossref]
09. Sen R, Tewari Ad, Sehgal Pk, Singh U, Sikka R, Sen J. Clinico-haematological profile in acute and chronic plasmodium falciparum malaria in children. J Com Dis. 1994;26(1)31-38.

[

Crossref]

10. Warrell Da, Turner Gdh, Francis N. Pathology and pathophysiology of human malaria In gilles $\mathrm{hm}$, warrell da, editors Essential malariology. 4th ed, London- Arnold. 2002;236-251. [Crossref]

11. Purohit M. $90 \%$ of malarial deaths happen in rural India. Ins Malar Paras Ento Q. 2015, July 24.

Available from [Article:http://www.impeqn.org.vn/impe-qn/en/portal/InfoDetail.jsp? area58\&cat $=1025 \& I D=934]$ [Crossref]

12. Echieverri M, Tobon A, Alvarez G, Carmona J, Blair S. Clinical and laboratory findings of plasmodium vivax malaria in colombia. Rev Inst Med Trop. 2003;45(1)29-34.

doi: [Article:http://dx.doi.org/10.1590/S003646652003000100006][Crossref]

13. Ladhani S, Lowe B, Cole Ao, Kowuondo K, Newton RJC. Changes in white blood cells and platelets in children with falciparum malariarelationship to disease outcome. Brit J Haematol. 2002;119(3)839-847.

doi: [Article:https://doi.org/10.1046/j.13652141.2002.03904.x][Crossref]

14. Patel P, Vijapura T, Patel N, Gajjar D. Rising incidence of Malaria Ahmedabad. Int J Med Sci Public Health. 2011-2012-2013;2(3)568-571. doi: [Article:http://dx.doi.org/10.5455/ijmsph.2013.1604 20131][Crossref]

15. Kevadiya SM, Patel MM, Modi J, Gamit B, Patel PR, Padsada S. Characteristic and trends of malaria in Surat district of Gujarat- a hospitalbased study. Int J Res Med Sci. 2014; 2(1)151153.

doi:

10.5455/2320-6012.ijrms20140230

[Article:https://dx.doi.org/][Crossref]

16. WHO. Basic malaria microscopy, Part ILearner's guide. 2nd ed, Geneva- World Health Organization. 2010, p-21.

[Crossref] 
17. Panchal PD, Trivedi MB, Shethwala N, Khatri HS. A study of prevalence and seasonal trends of different malarial species in district hospital. Int J Res Med Sci. 2016;4(9)4155-4157.

doi: [Article:http://dx.doi.org/10.18203/23206012.ijrms20162952][Crossref]

18. Solanki SJ, Shah R, Patel S, Singh N. Study of 100 cases of complicated plasmodium Falciparum malaria. Int J Sci Res. 2013;2(10)12.18

[Crossref]

19. Bashawri L, Mandil A, Bahnassy A, Ahmed M. Malaria- haematological aspects. Ann Saudi Med. 2002;22(5-6)372-377.

doi: [Article:https://doi.org/10.5144/02564947.2002.372][Crossref]
20. Richards MW, Behrens RH, Doherty JF. Hematologic changes in Acute, Imported Plasmodium falciparum Malaria. Am J Trop Med Hyg. 1998;59(6)859.

[Crossref] ]

21. Jadhav UM, Patkar VS, Kadam NN. Thrombocytopenia in Malaria - Correlation with Type and Severity of Malaria. J Assoc Physicians India. 2004;52(2)615-618.

[Crossref]

22. Akhtar S, Raghvendra G, Mahore S, Maimoon S. Hematological changes in malaria- $A$ comparative study. J Pharm Bio Sci. 2012;2(4)15-19.

doi: [Article:https://dx.doi.org/10.9790/30080241519][Crossref] 